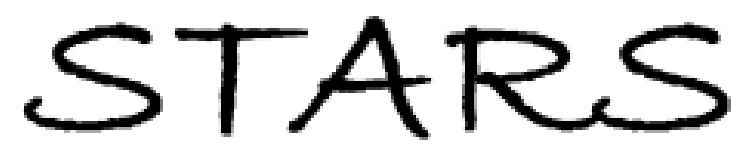

University of Central Florida

STARS

$1-1-2011$

\title{
Influence of growth rate on the epitaxial orientation and crystalline quality of $\mathrm{CeO} 2$ thin films grown on $\mathrm{Al} 2 \mathrm{O3}(0001)$
}

\author{
M. I. Nandasiri \\ P. Nachimuthu \\ T. Varga \\ V. Shutthanandan \\ W. Jiang
}

See next page for additional authors

Find similar works at: https://stars.library.ucf.edu/facultybib2010

University of Central Florida Libraries http://library.ucf.edu

This Article is brought to you for free and open access by the Faculty Bibliography at STARS. It has been accepted for inclusion in Faculty Bibliography 2010 s by an authorized administrator of STARS. For more information, please contactSTARS@ucf.edu.

\section{Recommended Citation}

Nandasiri, M. I.; Nachimuthu, P.; Varga, T.; Shutthanandan, V.; Jiang, W.; Kuchibhatla, Satyanarayana V. N. T.; Thevuthasan, S.; Seal, S.; and Kayani, A., "Influence of growth rate on the epitaxial orientation and crystalline quality of CeO2 thin films grown on Al203(0001)" (2011). Faculty Bibliography 2010s. 1705. https://stars.library.ucf.edu/facultybib2010/1705

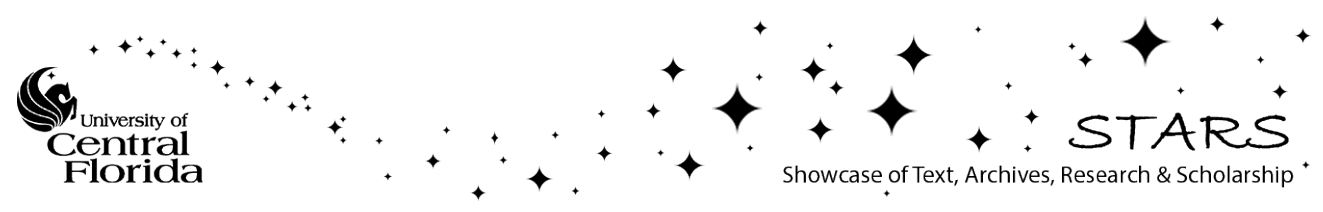




\section{Authors}

M. I. Nandasiri, P. Nachimuthu, T. Varga, V. Shutthanandan, W. Jiang, Satyanarayana V. N. T. Kuchibhatla, S. Thevuthasan, S. Seal, and A. Kayani 


\section{Influence of growth rate on the epitaxial orientation and crystalline quality of $\mathrm{CeO}_{2}$ thin films grown on $\mathrm{Al}_{2} \mathrm{O}_{3}(0001)$}

Cite as: J. Appl. Phys. 109, 013525 (2011); https://doi.org/10.1063/1.3525558

Submitted: 10 September 2010 . Accepted: 06 November 2010 . Published Online: 14 January 2011

M. I. Nandasiri, P. Nachimuthu, T. Varga, V. Shutthanandan, W. Jiang, Satyanarayana V. N. T. Kuchibhatla, S. Thevuthasan, S. Seal, and A. Kayani

\section{ARTICLES YOU MAY BE INTERESTED IN}

Growth-rate induced epitaxial orientation of $\mathrm{CeO}_{2}$ on $\mathrm{Al}_{2} \mathrm{O}_{3}(0001)$

Applied Physics Letters 94, 204101 (2009); https://doi.org/10.1063/1.3139073

Microstructural evolution during film growth

Journal of Vacuum Science \& Technology A 21, S117 (2003); https://doi.org/10.1116/1.1601610

Epitaxial growth of $\mathrm{SrTiO}_{3}$ films on $\mathrm{CeO}_{2}$ /yttria-stabilized zirconia/Si(001) with $\mathrm{TiO}_{2}$ atomic layer by pulsed-laser deposition

Applied Physics Letters 83, 4815 (2003); https://doi.org/10.1063/1.1631741

\section{Applied Physics Reviews}

Now accepting original research 


\title{
Influence of growth rate on the epitaxial orientation and crystalline quality of $\mathrm{CeO}_{2}$ thin films grown on $\mathrm{Al}_{2} \mathrm{O}_{3}(0001)$
}

\author{
M. I. Nandasiri, ${ }^{1,2, a)}$ P. Nachimuthu, ${ }^{2}$ T. Varga, ${ }^{2}$ V. Shutthanandan, ${ }^{2}$ W. Jiang, ${ }^{2}$ \\ Satyanarayana V. N. T. Kuchibhatla, ${ }^{2}$ S. Thevuthasan, ${ }^{2, b)}$ S. Seal, ${ }^{3}$ and A. Kayani ${ }^{1}$ \\ ${ }^{1}$ Department of Physics, Western Michigan University, Kalamazoo, Michigan 49008, USA \\ ${ }^{2}$ EMSL, Pacific Northwest National Laboratory, Richland, Washington 99354, USA \\ ${ }^{3}$ AMPAC, NSTC, University of Central Florida, Orlando, Florida 32816, USA
}

(Received 10 September 2010; accepted 6 November 2010; published online 14 January 2011)

Growth rate-induced epitaxial orientations and crystalline quality of $\mathrm{CeO}_{2}$ thin films grown on $\mathrm{Al}_{2} \mathrm{O}_{3}(0001)$ by oxygen plasma-assisted molecular beam epitaxy were studied using in situ and ex situ characterization techniques. $\mathrm{CeO}_{2}$ grows as three-dimensional (3D) islands and two-dimensional layers at growth rates of $1-7 \AA / \mathrm{min}$ and $\geq 9 \AA / \mathrm{min}$, respectively. The formation of epitaxial $\mathrm{CeO}_{2}(100)$ and $\mathrm{CeO}_{2}(111)$ thin films occurs at growth rates of $1 \AA / \mathrm{min}$ and $\geq 9 \AA / \mathrm{min}$, respectively. Glancing-incidence x-ray diffraction measurements have shown that the films grown at intermediate growth rates $(2-7 \AA / \mathrm{min})$ consist of polycrystalline $\mathrm{CeO}_{2}$ along with $\mathrm{CeO}_{2}(100)$. The thin film grown at $1 \AA$ /min exhibits six in-plane domains, characteristic of well-aligned $\mathrm{CeO}_{2}(100)$ crystallites. The content of the poorly aligned $\mathrm{CeO}_{2}(100)$ crystallites increases with increasing growth rate from 2 to $7 \AA / \mathrm{min}$, and three out of six in-plane domains gradually decrease and eventually disappear, as confirmed by XRD pole figures. At growth rates $\geq 9 \AA / \mathrm{min}, \mathrm{CeO}_{2}(111)$ film with single in-plane domain was identified. The formation of $\mathrm{CeO}_{2}(100) 3 \mathrm{D}$ islands at growth rates of $1-7 \AA / \mathrm{min}$ is a kinetically driven process unlike at growth rates $\geq 9 \AA /$ min which result in an energetically and thermodynamically more stable $\mathrm{CeO}_{2}(111)$ surface. (C) 2011 American Institute of Physics. [doi:10.1063/1.3525558]

\section{INTRODUCTION}

Cerium oxide $\left(\mathrm{CeO}_{2}\right)$ is one of the extensively studied functional materials; however, it continues to attract attention because of its unique properties that led to a wide range of applications in catalysis, ${ }^{1,2}$ state-of-the-art microelectronics, and medical biology ${ }^{3}$ as an oxygen buffer due to its strong redox potential. There is also a considerable interest in doped cerium oxides $^{4-6}$ as electrolyte materials in intermediatetemperature solid oxide fuel cells, because of their high ionic conductivity and compatibility with electrodes. ${ }^{7,8}$ $\mathrm{CeO}_{2}$-based materials are also being used in resistive oxygen gas sensors as oxygen sensing platforms. ${ }^{9,10}$ Furthermore, epitaxial $\mathrm{CeO}_{2}$ thin films grown on various substrates by different techniques have also been extensively studied as driven by the need for fundamental understanding of their unique properties. ${ }^{11-14}$

Most of these thin films involve low-index surfaces of $\mathrm{CeO}_{2}$, which have been studied theoretically by molecular dynamics simulations ${ }^{15,16}$ and density functional theory calculations. ${ }^{17,18}$ Both theoretical and experimental studies show that the surface potential, stability, and oxygen vacancy formation depend on the epitaxial orientation of $\mathrm{CeO}_{2}$ thin films grown on a given substrate. Surface energy calculations confirmed that $\mathrm{CeO}_{2}(111)$ is the most stable surface, and has the lowest surface energy, ${ }^{19}$ which makes this surface suitable for many applications. It is also the most closely packed surface with less surface relaxation. ${ }^{16}$ The stability of the

\footnotetext{
a)Electronic mail: manjula@pnl.gov.

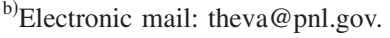

$\mathrm{CeO}_{2}(111)$ surface was also confirmed by experimental studies including x-ray photoelectron spectroscopy (XPS) and low-energy electron diffraction. ${ }^{20}$ On the other hand, the $\mathrm{CeO}_{2}(100)$ surface is relatively less stable and requires lower energy to create oxygen vacancies. ${ }^{21}$ Theoretical simulations have suggested that the $\mathrm{CeO}_{2}(100)$ surface is unstable due to a non-zero dipole moment perpendicular to the surface. ${ }^{22} \mathrm{In}$ general, the (100) surfaces with fluorite structure have an infinite surface energy, which can be reduced by surface roughening, surface charge relocation, surface defects, and surface reconstruction. ${ }^{23,24}$ Theoretical studies further predicted that the removal of half monolayer of oxygen at the $\mathrm{CeO}_{2}(100)$ surface would neutralize and stabilize the structure, ${ }^{19}$ which is also confirmed by angle-resolved mass spectroscopy of recoiled ions. ${ }^{25}$ Since low-index surfaces of $\mathrm{CeO}_{2}$ thin films exhibit different properties, it is of significance to understand their surface structure and property relationships. However, because of the commercially unavailable high quality $\mathrm{CeO}_{2}$ single crystals, it is important to synthesize pristine thin films of $\mathrm{CeO}_{2}$ with different epitaxial orientations on a given substrate.

Recently, we have been synthesizing high quality single crystal $\mathrm{CeO}_{2}$ thin films on YSZ(111), $\mathrm{SrTiO}_{3}(100)$, and $\mathrm{Al}_{2} \mathrm{O}_{3}(0001)$ substrates using molecular beam epitaxy. ${ }^{4-6,11,26}$ Furthermore, various characterization capabilities have been used to understand the influence of growth temperature, film thickness, and oxygen partial pressure on the surface properties of $\mathrm{CeO}_{2}$ thin films. However, the influence of growth rate on the surface properties of $\mathrm{CeO}_{2}$ is relatively unexplored, ${ }^{27}$ although the effects of growth rate 
on the structural, optical and electrical properties of the other metal oxides have been studied. ${ }^{28-30}$ Burmann et al. have investigated the influence of the deposition rate on the growth of $\mathrm{YBa}_{2} \mathrm{CuO}_{7-\mathrm{x}}$ thin films, where high and low growth rates favor a-axis and c-axis growth orientations, respectively. ${ }^{31}$ In the present study, we show the effects of growth rate on the epitaxial orientation of $\mathrm{CeO}_{2}$ thin films grown on $\mathrm{Al}_{2} \mathrm{O}_{3}(0001)$, and their crystalline quality including the alignment of crystallites and in-plane domains. Various in situ and ex situ characterization techniques including model structures were utilized to explain the physics of the formation of more complex polar and nonpolar surfaces of $\mathrm{CeO}_{2}$ thin films as a function of growth rate.

\section{EXPERIMENTAL DETAILS}

Growth of $\mathrm{CeO}_{2}$ thin films on $\mathrm{Al}_{2} \mathrm{O}_{3}(0001)$ by oxygen plasma-assisted molecular beam epitaxy and their in situ characterization were carried out in a dual chamber ultrahigh vacuum (UHV) system. The chamber consists of metal evaporation sources, a UHV compatible electron cyclotron resonance oxygen plasma source, and reflection high-energy electron diffraction (RHEED) for real-time characterization of the thin film growth. ${ }^{32}$ High-purity cerium metal $(99.9 \%)$ was used as the source material in an electron beam evaporator. Growth rate of thin films was measured in situ by a quartz crystal oscillator (QCO) which was calibrated by analyzing the as-grown films using ex situ techniques, such as $\mathrm{x}$-ray reflectivity, Rutherford backscattering spectrometry, and XPS.

The $\mathrm{Al}_{2} \mathrm{O}_{3}(0001)\left(10 \times 10 \times 1 \mathrm{~mm}^{3}\right)$ substrates were ultrasonically cleaned in acetone for $\sim 10$ min prior to loading in the UHV system. The substrate in the chamber was then cleaned at $650{ }^{\circ} \mathrm{C}$ for $\sim 10 \mathrm{~min}$ by exposure to oxygen plasma operating at $200 \mathrm{~W}$ under $\sim 2 \times 10^{-5}$ Torr of $\mathrm{O}_{2}$. The $\mathrm{CeO}_{2}$ thin films were grown by directing the predetermined quantity of $\mathrm{Ce}$ metal flux on to the $\mathrm{Al}_{2} \mathrm{O}_{3}(0001)$ substrate at $650{ }^{\circ} \mathrm{C}$ in an activated oxygen plasma. The thin film growth was monitored using RHEED with $15 \mathrm{kV} \mathrm{e}^{-}$-beam at an incident angle of $\sim 3^{\circ}-5^{\circ}$. Thin films with different growth rates from 1 to $10 \AA / \mathrm{min}$ were grown by controlling the $\mathrm{Ce}$ metal flux using precalibrated QCO.

High-resolution x-ray diffraction (HRXRD) measurements for both in-plane and out-of-plane reflections were performed using four-circle Philips X'pert materials research diffractometer operating at $45 \mathrm{kV}$ and $40 \mathrm{~mA}$ with a fixed $\mathrm{Cu}$ anode. A hybrid monochromator, consisting of a four-bounce $\mathrm{Ge}(220)$ crystal and a $\mathrm{Cu}$ x-ray mirror, was employed in the incident beam path to provide monochromatic $\mathrm{x}$-rays from $\mathrm{Cu} K \alpha_{1} \quad(\lambda=0.154056 \mathrm{~nm}$ and $\Delta \lambda / \lambda=23 \mathrm{ppm})$ with a beam divergence of 12 arc sec. Glancing-incidence $\mathrm{x}$-ray diffraction (GIXRD) measurements were performed using Philips X'pert multipurpose diffractometer operating at 45 $\mathrm{kV}$ and $40 \mathrm{~mA}$ with a fixed $\mathrm{Cu}$ anode and a $\mathrm{Cu} \mathrm{x}$-ray mirror. The analysis of diffraction data was performed using JADE 8.5 and JPOWD 5.1 from Materials Data Inc. and PDF4 +database from ICSD. Ex situ atomic force microscopic (AFM) studies were carried out using the Digital Instrument (DI) Nanoscope IIIa multimode scanning probe microscope

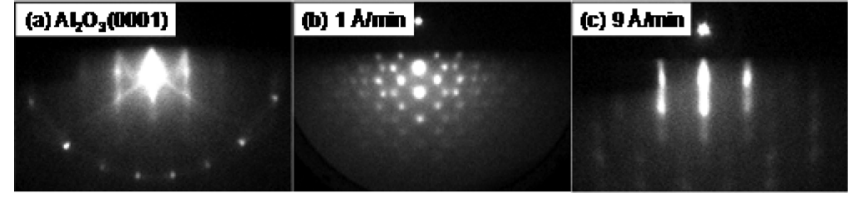

FIG. 1. In situ reflection RHEED patterns collected from (a) a clean $\mathrm{Al}_{2} \mathrm{O}_{3}(0001)$ surface following $\mathrm{CeO}_{2}$ growth on $\mathrm{Al}_{2} \mathrm{O}_{3}(0001)$ at $\sim 650{ }^{\circ} \mathrm{C}$ under $\sim 2.0 \times 10^{-5}$ Torr of $\mathrm{O}_{2}$ plasma at growth rates of (b) $1 \AA / \mathrm{min}$, and (c) $9 \AA / \mathrm{min}$.

under tapping mode. All the model structures were built using JPOWD 5.1 from Materials Data Inc. and PDF4 + database.

\section{RESULTS}

In general, the growth of crystalline thin films on single crystal substrates can be described as two-dimensional (2D) layer-by-layer growth, or three-dimensional (3D) island growth, or layer-plus-island growth (Stranski-Krastanov growth). ${ }^{33}$ Each of these growth modes results in certain surface morphology of the thin films. Therefore, monitoring the surface morphology of the thin films during growth will enable the identification and understanding of the mode of film growth. The in situ RHEED patterns collected from the clean $\mathrm{Al}_{2} \mathrm{O}_{3}(0001)$ surface and the $\mathrm{CeO}_{2}$ film on $\mathrm{Al}_{2} \mathrm{O}_{3}(0001)$ for the growth rates of 1 and $9 \AA / \mathrm{min}$ are shown in Fig. 1 as representative examples. The RHEED patterns from the $\mathrm{Al}_{2} \mathrm{O}_{3}(0001)$ substrate show sharp streaks following the oxygen plasma treatment, indicating a clean, flat surface. Following the $\mathrm{CeO}_{2}$ growth at growth rates $\leq 7 \AA / \mathrm{min}$, the RHEED patterns show spots throughout the growth processes, indicating 3D island growth. ${ }^{34}$ When the growth rate is increased beyond $7 \AA / \mathrm{min}$, the RHEED patterns show a transition from spots to streaks, indicating epitaxial layer growth.

AFM images recorded from $\mathrm{CeO}_{2}$ thin films grown on $\mathrm{Al}_{2} \mathrm{O}_{3}(0001)$ at growth rates of 1 and $9 \AA / \mathrm{min}$ are shown in Fig. 2. The average surface roughness is found to be within 5-10 $\AA$, indicating high-quality surfaces of the $\mathrm{CeO}_{2}$ thin films. The heights of these clusters are found to be $\sim 2.6 \mathrm{~nm}$ and $\sim 2.8 \mathrm{~nm}$ for $\mathrm{CeO}_{2}$ films grown at $1 \AA / \mathrm{min}$ and $9 \AA / \mathrm{min}$, respectively. About 50 individual clusters were randomly sampled and the average size of the clusters is found to be $\sim 11 \mathrm{~nm}$ and $\sim 37 \mathrm{~nm}$ for $\mathrm{CeO}_{2}$ films grown at $1 \AA / \mathrm{min}$ and $9 \AA /$ min, respectively.

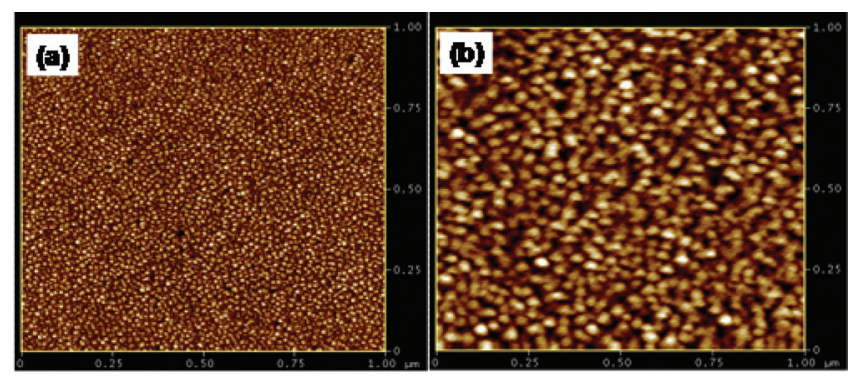

FIG. 2. (Color) AFM images recorded from $\mathrm{CeO}_{2}$ thin films grown on $\mathrm{Al}_{2} \mathrm{O}_{3}(0001)$ at growth rates of (a) $1 \AA / \mathrm{min}$ and (b) $9 \AA / \mathrm{min}$. The average surface roughness is found to be within 5-10 $\mathrm{A}$. 


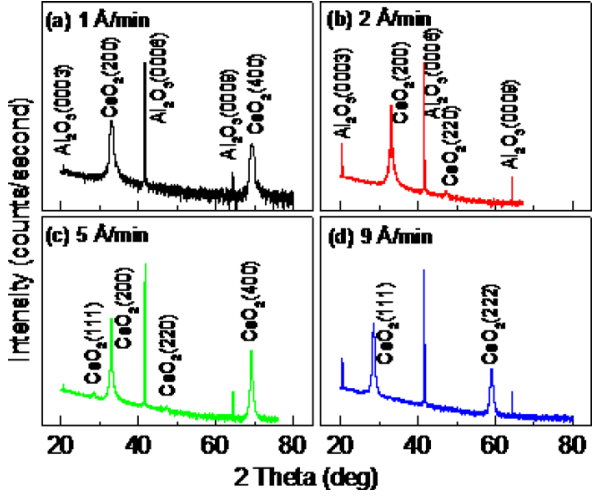

FIG. 3. (Color online) HRXRD patterns of $\mathrm{CeO}_{2}$ thin films grown on $\mathrm{Al}_{2} \mathrm{O}_{3}(0001$ ) at growth rates of (a) $1 \AA / \mathrm{min}$, (b) $2 \AA / \mathrm{min}$, (c) $5 \AA / \mathrm{min}$, and (d) $9 \AA / \mathrm{min}$.

HRXRD patterns measured from $\mathrm{CeO}_{2}$ thin films grown on $\mathrm{Al}_{2} \mathrm{O}_{3}(0001)$ for the growth rates of $1,2,5$, and $9 \AA / \mathrm{min}$ are shown in Fig. 3. The corresponding GIXRD patterns measured from these thin films are shown in Fig. 4 to identify any polycrystalline materials in these films. The HRXRD patterns show reflections from both $\mathrm{CeO}_{2}$ thin film and $\mathrm{Al}_{2} \mathrm{O}_{3}(0001)$ substrate. At $1 \AA /$ min growth rate, only $\mathrm{CeO}_{2}(200)$ and $\mathrm{CeO}_{2}(400)$ reflections were detected, suggesting that the thin film is epitaxial $\mathrm{CeO}_{2}(100)$. The GIXRD pattern reveals the absence of any polycrystalline material in this film as shown in Fig. 4(a). At $2 \AA / m i n, ~ H R X R D$ pattern shows $\mathrm{CeO}_{2}(200)$ with a weak $\mathrm{CeO}_{2}(220)$ reflection, suggesting that the thin film is mostly $\mathrm{CeO}_{2}(100)$ oriented. However, GIXRD pattern [Fig. 4(b)] shows (111), (220), (311), and (331) reflections from $\mathrm{CeO}_{2}$, confirming the presence of polycrystalline material. With increasing growth rate from 3 to $7 \AA / \mathrm{min}, \mathrm{CeO}_{2}(200)$ and $\mathrm{CeO}_{2}(400)$ reflections were detected with weak $\mathrm{CeO}_{2}(111)$ and $\mathrm{CeO}_{2}(220)$ reflections, indicating that the film is still mostly $\mathrm{CeO}_{2}(100)$ oriented. HRXRD pattern for $\mathrm{CeO}_{2}$ thin film grown at $5 \AA / \mathrm{min}$ is shown in Fig. 3(c) as a representative example. The GIXRD pattern [Fig. 4(c)] shows all the reflection peaks from $\mathrm{CeO}_{2}$, confirming the presence of polycrystalline material in the film. At growth rates $\geq 9 \AA / \mathrm{min}$, HRXRD patterns show only $\mathrm{CeO}_{2}(111)$ and $\mathrm{CeO}_{2}(222)$ reflections, indicating the growth of $\mathrm{CeO}_{2}(111)$-oriented thin film. While

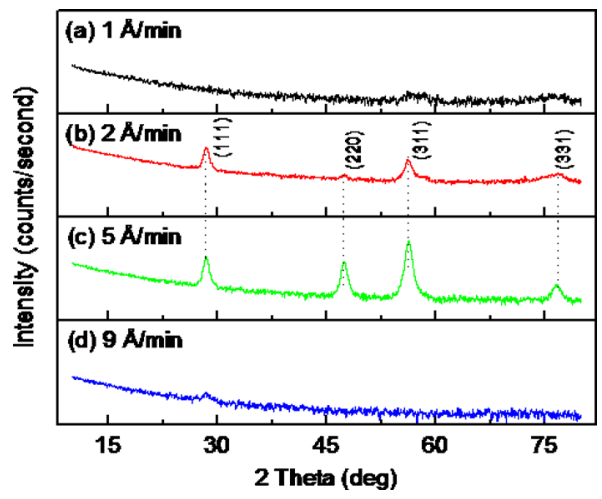

FIG. 4. (Color online) GIXRD patterns of $\mathrm{CeO}_{2}$ thin films grown on $\mathrm{Al}_{2} \mathrm{O}_{3}(0001)$ at growth rates of (a) $1 \AA / \mathrm{min}$, (b) $2 \AA / \mathrm{min}$, (c) $5 \AA / \mathrm{min}$, and (d) $9 \AA / \mathrm{min}$.

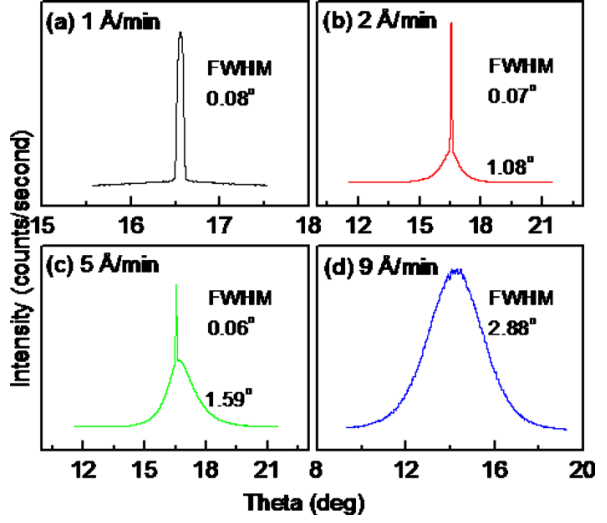

FIG. 5. (Color online) The x-ray rocking curves of $\mathrm{CeO}_{2}$ thin films grown on $\mathrm{Al}_{2} \mathrm{O}_{3}(0001)$ at growth rates of (a) $1 \AA / \mathrm{min}$, (b) $2 \AA / \mathrm{min}$, (c) $5 \AA / \mathrm{min}$, and (d) $9 \AA / \mathrm{min}$. The data $[(\mathrm{a})-(\mathrm{c})]$ is collected at the $\mathrm{CeO}_{2}(200)$ reflection, and (d) at the $\mathrm{CeO}_{2}(111)$ reflection.

HRXRD shows the change in the epitaxial orientation of $\mathrm{CeO}_{2}$ thin films with increasing growth rates, GIXRD indicates that the $\mathrm{CeO}_{2}$ films grow as single crystals at relatively lower and higher growth rates, but at intermediate growth rates $(2-7 \AA / \mathrm{min})$, minor polycrystalline $\mathrm{CeO}_{2}$ phases are present along with the $\mathrm{CeO}_{2}(100)$-oriented film.

To understand the crystalline quality of $\mathrm{CeO}_{2}$ thin films with increasing growth rates, $\mathrm{x}$-ray rocking curves were collected from $\mathrm{CeO}_{2}(200)$ reflection for the films grown at 1, 2, and $5 \AA / \mathrm{min}$, and $\mathrm{CeO}_{2}$ (111) reflection for the film grown at $9 \AA /$ min. The corresponding curves are shown in Fig. 5. At 1 $\AA /$ min, a narrow rocking curve with full width at half maximum (FWHM) value of $0.08^{\circ}$ shows well-oriented crystallites in $\mathrm{CeO}_{2}(100)$ epitaxial film. At intermediate growth rates (2-7 $\AA / \mathrm{min})$, the $\mathrm{x}$-ray rocking curves consist of an intense narrower peak superimposed on a less intense broader band. The narrower peak is attributed to relatively larger and well-aligned crystallites and the broader band is most likely from relatively smaller and poorly aligned crystallites as a result of significant strain. Both types of crystallites coexist in the $\mathrm{CeO}_{2}(100)$ oriented thin film. When increasing growth rate from 2 to $5 \AA / \mathrm{min}$, the FWHM of the narrower peak remains constant with decreasing area under the peak, but the FWHM of the broader band increases from $1.08^{\circ}$ to $1.59^{\circ}$ with an increasing area under the band, suggesting that the ratio of smaller and poorly aligned crystallites to larger and well-aligned crystallites increases. Similar observations were made on $\mathrm{ZnO}$ thin films grown on $\mathrm{Al}_{2} \mathrm{O}_{3}(0001)$, which is interpreted as a two-layer structure with poor and better structural quality near the interface and at the surface, respectively. ${ }^{35}$ Linker et al. have observed a mosaic distribution for ultrathin epitaxial $\mathrm{CeO}_{2}(100)$ films grown on r-plane sapphire by sputtering, where the narrow peak was ascribed to pseudomorphic growth. ${ }^{36}$ They have attributed the broader band in the mosaic distribution to the relaxed structure of $\mathrm{CeO}_{2}(100)$ resulting from incorporation of defects. The results from the $\mathrm{CeO}_{2}$ films show that increasing the growth rate from 1 to $5 \AA /$ min leads to a broadening of the rocking curves and the presence of polycrystalline $\mathrm{CeO}_{2}$. When increasing the growth rate to $\geq 9 \AA / \mathrm{min}$, the $\mathrm{CeO}_{2}$ thin films tend to grow layer-by-layer, which re- 

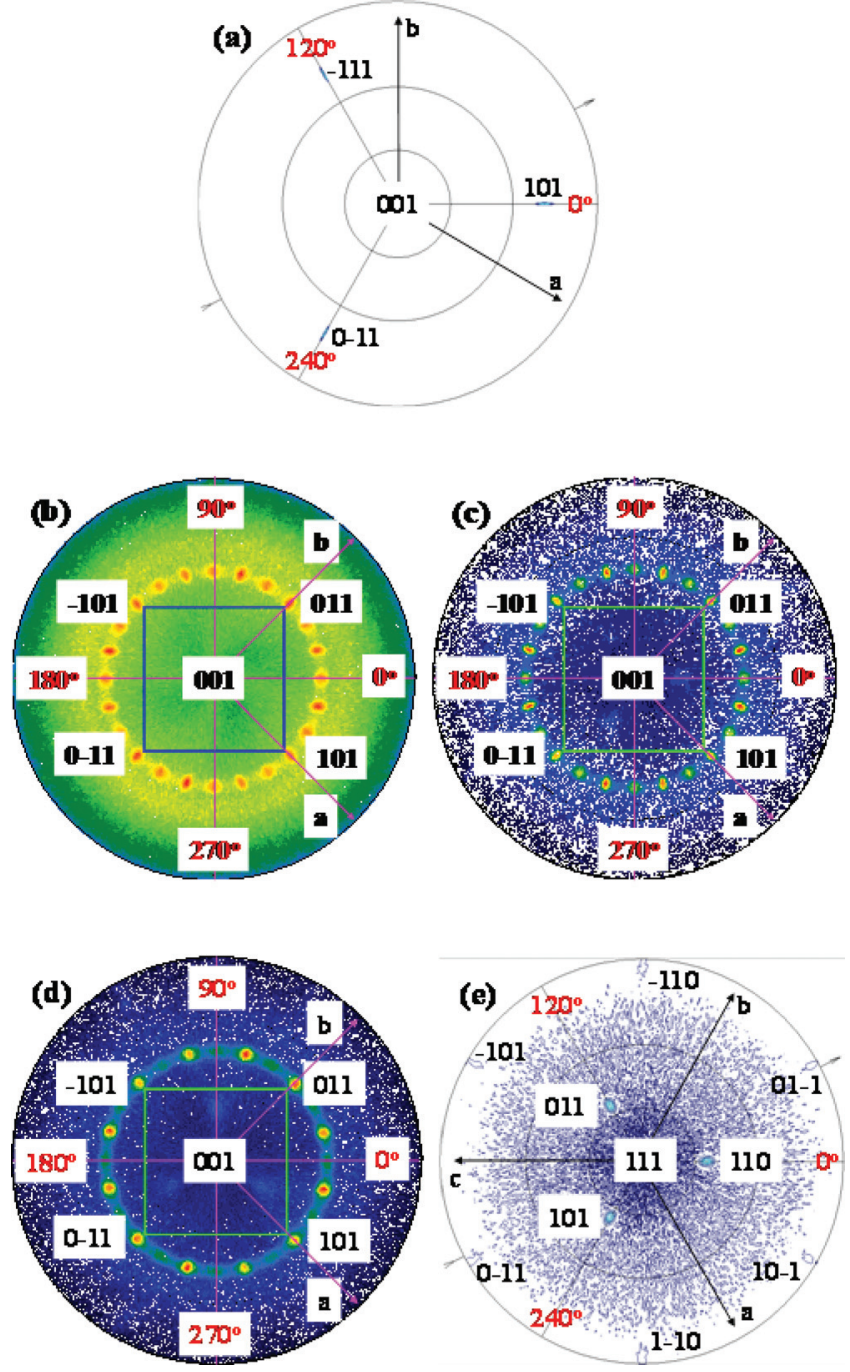

FIG. 6. (Color) $\mathrm{X}$-ray pole figures corresponding to the in-plane reflections of (a) $\mathrm{Al}_{2} \mathrm{O}_{3}$ (202) poles from an $\mathrm{Al}_{2} \mathrm{O}_{3}(0001)$ single crystal substrate, and $\mathrm{CeO}_{2}(220)$ poles from $\mathrm{CeO}_{2}(100)$, and $\mathrm{CeO}_{2}(111)$ thin films grown on $\mathrm{Al}_{2} \mathrm{O}_{3}(0001)$ with growth rates of (b) $1 \AA / \mathrm{min}$, (c) $2 \AA / \mathrm{min}$, (d) $5 \AA / \mathrm{min}$, and (e) $9 \AA / \mathrm{min}$. The elongation of the poles along the radial direction is an instrumental effect from the line-focused $\mathrm{x}$-ray optics.

sults in $\mathrm{CeO}_{2}(111)$ orientation. At the same time, the $\mathrm{x}$-ray rocking curve from the $\mathrm{CeO}_{2}(111)$ reflection becomes broader with an FWHM of $2.88^{\circ}$. It suggests that the $\mathrm{CeO}_{2}(111)$ oriented film contains poorly aligned crystallites due to strain induced by the lattice mismatch between $\mathrm{CeO}_{2}$ thin film and $\mathrm{Al}_{2} \mathrm{O}_{3}(0001)$ substrate.

In order to understand the epitaxial relationship between the $\mathrm{Al}_{2} \mathrm{O}_{3}(0001)$ substrate and $\mathrm{CeO}_{2}$ thin films with increasing growth rate, in-plane $\mathrm{x}$-ray pole-figure measurements were carried out at the $\mathrm{Al}_{2} \mathrm{O}_{3}(202)$ and $\mathrm{CeO}_{2}(220)$ reflections, respectively. These results are shown in Fig. 6. Since the $\mathrm{Al}_{2} \mathrm{O}_{3}(202)$ and $\mathrm{CeO}_{2}(220)$ reflections are parallel to the $\mathrm{Al}_{2} \mathrm{O}_{3}(101)$ and $\mathrm{CeO}_{2}(110)$ reflections, respectively, these low-index reflections are used in the following discussion for simplicity. It is worth mentioning, that the elongation of the poles along the radial direction is an instrumental effect from the line-focused $\mathrm{x}$-ray optics. The $\mathrm{Al}_{2} \mathrm{O}_{3}(0001)$ exhibits three in-plane $\mathrm{Al}_{2} \mathrm{O}_{3}(101)$ poles at $72.40^{\circ}$ tilt, showing the single crystal nature of the substrate. In principle, $\mathrm{CeO}_{2}(100)$ single crystal with one in-plane domain should show four in-plane $\mathrm{CeO}_{2}(110)$ poles at $45^{\circ}$ tilt. However, the $\mathrm{CeO}_{2}(100)$ film grown on $\mathrm{Al}_{2} \mathrm{O}_{3}(0001)$ at $1 \AA / \mathrm{min}$ shows twenty-four inplane $\mathrm{CeO}_{2}(110)$ poles, suggesting that this thin film contains six in-plane domains. The film grown at $2 \AA / \mathrm{min}$ also shows twenty-four in-plane $\mathrm{CeO}_{2}(110)$ poles, although a half of them are weaker in intensity. When increasing the growth rate to $5 \AA / \mathrm{min}$, only twelve in-plane $\mathrm{CeO}_{2}(110)$ poles were detected; however, a ring pattern characteristic of polycrystalline $\mathrm{CeO}_{2}$ is also observed in the background. By combining the results from the rocking curves and the in-plane polefigure measurements, it is clear that the relatively smaller and poorly aligned crystallites are accumulated with increasing growth rate from 2 to $7 \AA / \mathrm{min}$, which are reflected in the broadening of the rocking curves and the larger area under the curves. The poorly aligned crystallites do not seem to contribute significantly to the pole intensity. However, a fraction of larger and well-aligned crystallites is still present in these films, which contribute to the pole intensity. In addition, these well-aligned crystallites are superimposed with poorly aligned crystallites and preferentially occupy three out of six in-plane domains. As a result, the twenty-four in-plane $\mathrm{CeO}_{2}(110)$ poles detected for the film grown at 1 $\AA /$ min become twelve poles for the film grown at $5 \AA / \mathrm{min}$. Furthermore, with the growth rate increased to $9 \AA / \mathrm{min}$, the $\mathrm{CeO}_{2}$ thin films grow layer-by-layer, resulting in epitaxial $\mathrm{CeO}_{2}(111)$ with poorly aligned crystallites. The $\mathrm{CeO}_{2}(111)$ single crystal should show three in-plane $\mathrm{CeO}_{2}(110)$ poles at $35.26^{\circ}$ tilt. This is indeed observed for the film grown at 9 $\AA /$ min, suggesting that this film has a single in-plane domain. However, while this film is composed of poorly aligned crystallites, experimentally it is still feasible to measure its pole figure with weaker pole intensity.

\section{DISCUSSION}

Change in the epitaxial orientation of a thin film grown on a single crystal surface as a function of growth rate is unique and unusual. In general, if the lattice mismatch can be accommodated, high-quality single crystal thin films grow with a specific epitaxial orientation on a given single crystal substrate surface at a particular growth temperature, regardless of the growth rate. If the strain associated with the lattice mismatch cannot be accommodated in the film, then it may result in a polycrystalline film or the film may break down to clusters. It appears that, in this particular system, and under specific conditions, the lattice mismatch is just enough to keep the high-quality single crystal growth. However, the epitaxial orientation of the $\mathrm{CeO}_{2}$ thin film switches from (100) to (111) with increasing the amount of cerium atoms deposited on the $\mathrm{Al}_{2} \mathrm{O}_{3}(0001)$ surface. This work provides an experimental evidence for growth rate-induced switching of the epitaxial orientation of the $\mathrm{CeO}_{2}$ thin film. Here, we propose that the switching of the orientation from $\mathrm{CeO}_{2}(100)$ to $\mathrm{CeO}_{2}(111)$ occurs through a transition from kinetically driven growth under low growth rate to the formation of more thermodynamically stable surface at higher growth rates.

A number of theoretical studies have shown that the 

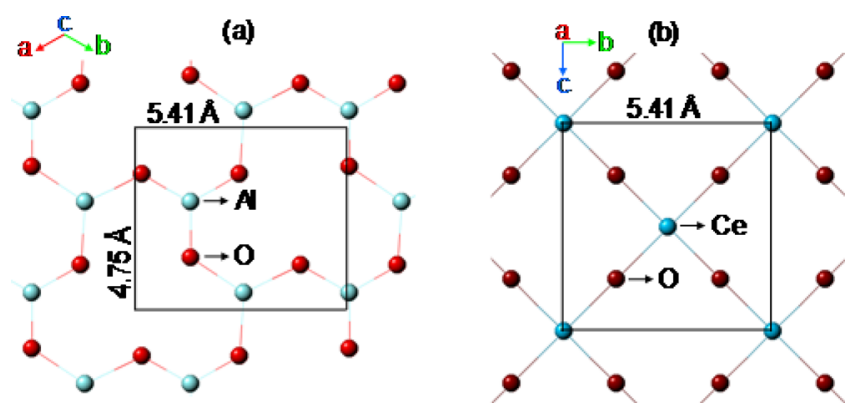

FIG. 7. (Color online) (a) Aluminum bilayer and an oxygen sublattice in $\mathrm{Al}_{2} \mathrm{O}_{3}(0001)$. Each aluminum and oxygen atom is coordinated to six oxygen and four aluminum atoms, respectively. The solid lines indicate the repeating units in the $\mathrm{Al}_{2} \mathrm{O}_{3}(0001)$ plane, and one of the six possible arrangements of $\mathrm{CeO}_{2}(100)$ on top of $\mathrm{Al}_{2} \mathrm{O}_{3}(0001)$. (b) Cerium and oxygen sublattices in $\mathrm{CeO}_{2}(100)$. The solid lines indicate a cubic unit cell in which each cerium and oxygen atom is coordinated to eight $\mathrm{O}$ and four $\mathrm{Ce}$ atoms, respectively.

$\mathrm{CeO}_{2}(111)$ surface is energetically and thermodynamically more stable compared to $\mathrm{CeO}_{2}(100)$ surface. ${ }^{16,17,19}$ Furthermore, it is shown that the planar density of (111) planes in a typical face-centered cubic structure is almost four times larger compared to (100) planes, indicating that the number of atoms required to grow the $\mathrm{CeO}_{2}(111)$ plane is more than the $\mathrm{CeO}_{2}(100)$ plane as a result of the packing differences in these planes. ${ }^{27}$ In the present study, the film grows as $3 \mathrm{D}$ islands at $1 \AA / \mathrm{min}$ forming epitaxial $\mathrm{CeO}_{2}(100)$ on $\mathrm{Al}_{2} \mathrm{O}_{3}(0001)$, suggesting that there are not enough atoms available to form the thermodynamically stable $\mathrm{CeO}_{2}(111)$ surface. Instead, the atoms are forced to take the next energetically favorable $\mathrm{CeO}_{2}(100)$ surface, indicating that it is a kinetically driven process. When the growth rate is increased from $1 \AA / m i n$ to $2-7 \AA / m i n$, the thin film still grows as $3 \mathrm{D}$ islands forming $\mathrm{CeO}_{2}(100)$. There are still not enough atoms available to form $\mathrm{CeO}_{2}(111)$. In addition, there may not be enough time available for all the atoms to move around and find stable equilibrium positions; hence, a fraction of $\mathrm{CeO}_{2}(100)$ crystallites is poorly aligned, and this fraction increases with increasing growth rate. When increasing the growth rate to $\geq 9 \AA / \mathrm{min}$, thin films grow as layer-by-layer forming energetically and thermodynamically stable $\mathrm{CeO}_{2}(111)$ surface, which agrees with many of the theoretical predictions. ${ }^{16,19,37}$

While the growth of $\mathrm{CeO}_{2}(100)$ on $\mathrm{Al}_{2} \mathrm{O}_{3}(0001)$ is a kinetic process forming $3 \mathrm{D}$ islands, the presence of multiple in-plane domains in $\mathrm{a} \mathrm{CeO}_{2}(100)$ film is not well-understood. To shed light on the lattice mismatch and possible in-plane domains, model structures of $\mathrm{Al}_{2} \mathrm{O}_{3}(0001)$ and $\mathrm{CeO}_{2}$ in (100) and (111) orientations were investigated. An aluminum (Al) bilayer and an oxygen $(\mathrm{O})$ sublattice from $\mathrm{Al}_{2} \mathrm{O}_{3}(0001)$, along with cerium $(\mathrm{Ce})$ and oxygen sublattices from $\mathrm{CeO}_{2}(100)$, are shown in Fig. 7. In $\mathrm{Al}_{2} \mathrm{O}_{3}(0001)$, each aluminum and oxygen atoms are coordinated to six oxygen atoms from two oxygen sublattices and four aluminum atoms from two aluminum bilayers, respectively. The solid lines indicate the repeating units in the $\mathrm{Al}_{2} \mathrm{O}_{3}(0001)$ plane, and one of the six possible arrangements of $\mathrm{CeO}_{2}(100)$ on top of $\mathrm{Al}_{2} \mathrm{O}_{3}(0001)$. The solid lines in $\mathrm{CeO}_{2}(100)$ indicate a cubic unit cell in which each cerium and oxygen atoms are coordinated to eight oxygen atoms from two oxygen sublattices

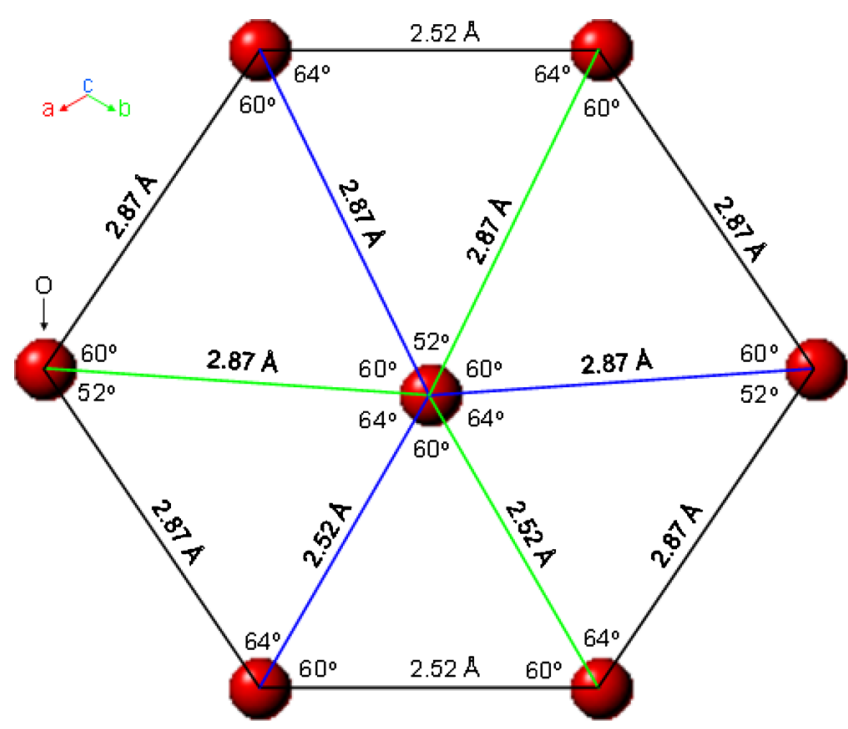

FIG. 8. (Color online) Oxygen sublattice of $\mathrm{Al}_{2} \mathrm{O}_{3}(0001)$. The distance and the angle between the oxygen atoms are shown to be different for all six rectangular units of oxygen atoms in $\mathrm{Al}_{2} \mathrm{O}_{3}(0001)$ that can bind to $\mathrm{Ce}$ in $\mathrm{CeO}_{2}(100)$.

and four cerium atoms from two cerium sublattices, respectively. The distance and the angle between the cerium atoms in $\mathrm{CeO}_{2}(100)$ are $3.83 \AA$ and $90^{\circ}$, and are $2.71 \AA$ and $90^{\circ}$ for oxygen atoms, respectively. The structures shown here for both $\mathrm{Al}_{2} \mathrm{O}_{3}(0001)$ and $\mathrm{CeO}_{2}(100)$ are oxygen terminated surfaces, each oxygen atom bonded to two cations, and it can bind to two more cations. When a cerium sublattice from $\mathrm{CeO}_{2}(100)$ cubic unit cell is placed on top of the $\mathrm{Al}_{2} \mathrm{O}_{3}(0001)$, as marked by the solid lines, to bind each cerium atoms to four oxygen atoms from the oxygen sublattice in $\mathrm{Al}_{2} \mathrm{O}_{3}(0001)$, the cerium sublattice has to compress along the c-axis by $\sim 14 \%$. No compression is required along the b-axis. Furthermore, each oxygen atom has to bind to two cerium atoms, and each cerium atom needs to bind to four oxygen atoms from the oxygen sublattice in $\mathrm{Al}_{2} \mathrm{O}_{3}(0001)$. These oxygen atoms are not at the same distance or angle from each other, unlike in the oxygen sublattice of $\mathrm{CeO}_{2}(100)$. The oxygen sublattice in $\mathrm{Al}_{2} \mathrm{O}_{3}(0001)$ including the distance and the angle between these oxygen atoms is shown in Fig. 8 to highlight the differences in all quadrangle units of oxygen atoms that can bind to cerium atoms in $\mathrm{CeO}_{2}(100)$. The distance and the angle between the oxygen atoms from the quadrangle units in $\mathrm{Al}_{2} \mathrm{O}_{3}(0001)$ are found to be $2.52 \AA$ and $2.87 \AA$, and $52^{\circ}, 60^{\circ}, 64^{\circ}, 112^{\circ}$, and $124^{\circ}$, respectively. All six of these repeating rectangular units of oxygen atoms are nonequivalent either in sequence of distance or angle. However, the cerium atoms arrive from the top layer during the slow growth processes $(1 \AA / \mathrm{min})$, and six of each rectangular units of oxygen atoms from the oxygen sublattice in $\mathrm{Al}_{2} \mathrm{O}_{3}(0001)$ are unique. These oxygen atoms bind to cerium atoms which produces six in-plane domains by keeping $\mathrm{CeO}_{2}(100)$ out-of-plane. Furthermore, $\mathrm{Al}_{2} \mathrm{O}_{3}(0001)$ has the hexagonal structure with sixfold rotational symmetry along the c-axis, which explains the six inplane domains in $\mathrm{CeO}_{2}(100)$ grown on $\mathrm{Al}_{2} \mathrm{O}_{3}(0001)$. Each of these six in-plane domains in $\mathrm{CeO}_{2}(100)$ is $60^{\circ}$ to each other, and as a result the lattice mismatch between $\mathrm{Al}_{2} \mathrm{O}_{3}(0001)$ 


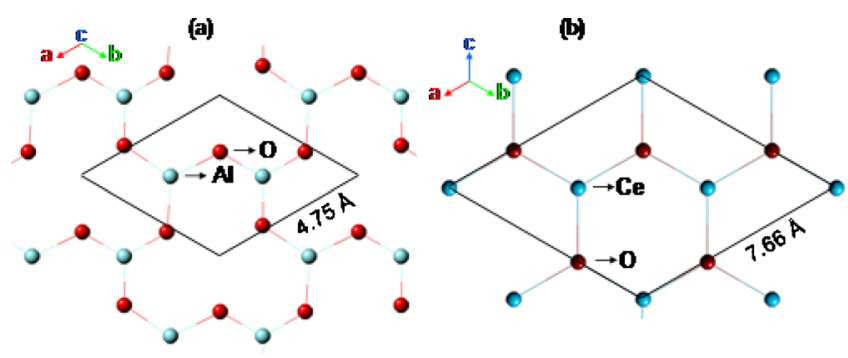

FIG. 9. (Color online) (a) Aluminum bilayer and an oxygen sublattice in $\mathrm{Al}_{2} \mathrm{O}_{3}(0001)$. Each aluminum and oxygen atom is coordinated to six oxygen and four aluminum atoms, respectively. The solid lines indicate a hexagonal unit cell, and the arrangement of $\mathrm{CeO}_{2}(111)$ on top of $\mathrm{Al}_{2} \mathrm{O}_{3}(0001)$. (b) Cerium and oxygen sublattices of $\mathrm{CeO}_{2}(111)$. The solid lines indicate a hexagonal unit in $\mathrm{CeO}_{2}(111)$ that can grow on top of $\mathrm{Al}_{2} \mathrm{O}_{3}(0001)$ as shown Each cerium and oxygen atom is coordinated to eight oxygen and four cerium atoms, respectively.

and $\mathrm{CeO}_{2}(100)$ is minimized significantly. This, in turn, leads to a narrow out-of-plane $\mathrm{CeO}_{2}(100)$ rocking curve with a FWHM value of $0.08^{\circ}$ showing well-oriented crystallites in the $\mathrm{CeO}_{2}(100)$ direction. Three of the six in-plane domains are becoming less prominent when the growth rate is increased from $1 \AA / \mathrm{min}$ to $2-7 \AA / \mathrm{min}$. This is probably due to the lack of sufficient time to stabilize the cerium atoms on all of the rectangular units of oxygen atoms from the oxygen sublattice in $\mathrm{Al}_{2} \mathrm{O}_{3}(0001)$, which may not be energetically favorable, and results in poorly aligned $\mathrm{CeO}_{2}(100)$ crystallites. The formation of poorly aligned crystallites is reflected in the $\mathrm{x}$-ray rocking curves where an intense narrower peak is superimposed on a less intense broader one. Furthermore, the intensity of the broader peak component increases with increasing growth rate. This, in turn, reduces, and eventually eliminates, three out of six in-plane domains with increasing growth rate from 2 to $7 \AA / \mathrm{min}$.

The model structure of $\mathrm{CeO}_{2}(111)$ growth on $\mathrm{Al}_{2} \mathrm{O}_{3}(0001)$ is shown in Fig. 9. The solid lines indicate a hexagonal unit cell of $\mathrm{Al}_{2} \mathrm{O}_{3}(0001)$, and a possible arrangement of a hexagonal $\mathrm{CeO}_{2}(111)$ unit on top of $\mathrm{Al}_{2} \mathrm{O}_{3}(0001)$, as supported by the HRXRD [Fig. 3(d)] and in-plane polefigure measurements [Fig. 6(e)]. The distance and the angle between the cerium atoms in $\mathrm{CeO}_{2}(111)$ are $3.83 \AA$ and $120^{\circ}$, respectively, and same is true for oxygen atoms as well. When a cerium sublattice from the $\mathrm{CeO}_{2}(111)$ hexagonal unit is placed on top of the $\mathrm{Al}_{2} \mathrm{O}_{3}(0001)$ to bind each cerium atoms to three oxygen atoms from the oxygen sublattice in $\mathrm{Al}_{2} \mathrm{O}_{3}(0001)$, the cerium sublattice has to compress in the direction of all three axes by $\sim 24 \%$ in order to accommodate the $\mathrm{CeO}_{2}(111)$ unit. As a result, the x-ray rocking curve of the $\mathrm{CeO}_{2}(111)$ reflection shows a broader band with an FWHM of $2.88^{\circ}$, which is characteristic of poorly aligned crystallites. However, the thin film grows layer-bylayer forming an energetically and thermodynamically stable $\mathrm{CeO}_{2}(111)$ surface.

\section{CONCLUSIONS}

This work provides experimental evidence that the growth rate can induce a change in the epitaxial orientation of $\mathrm{CeO}_{2}$ thin films grown on $\mathrm{Al}_{2} \mathrm{O}_{3}(0001)$ using molecular beam epitaxy. By combining $\mathrm{x}$-ray and electron diffraction measurements with structural models of crystalline sublattices of aluminum, cerium, and oxygen, it has been concluded that the formation of the $\mathrm{CeO}_{2}(100) 3 \mathrm{D}$ islands for growth rates of $1-7 \AA / \mathrm{min}$ is a kinetically driven process, while the formation of $\mathrm{CeO}_{2}(111)$ layers with growth rates $\geq 9 \AA /$ min results in an energetically and thermodynamically more stable surface. At intermediate growth rates (2-7 $\AA / \mathrm{min}$ ), the thin films contain polycrystalline $\mathrm{CeO}_{2}$ along with oriented $\mathrm{CeO}_{2}(100)$ crystallites. Furthermore, it is shown systematically with a detailed $\mathrm{x}$-ray pole-figure analysis that the growth of $\mathrm{CeO}_{2}$ film evolves through different stages as a function of growth rate from $\mathrm{CeO}_{2}(100)$ at 1 $\AA /$ min characterized by $3 \mathrm{D}$ islands, to $\mathrm{CeO}_{2}(111)$ at $\geq 9 \AA /$ min growing as a $2 \mathrm{D}$ epitaxial film.

\section{ACKNOWLEDGMENTS}

The research was performed using EMSL, a national scientific user facility sponsored by the Department of Energy's Office of Biological and Environmental Research and located at Pacific Northwest National Laboratory (PNNL). PNNL is operated for the U.S. DOE by Battelle Memorial Institute under Contract No. DE-AC05-76RL01830.

${ }^{1}$ Q. Fu, H. Saltsburg, and M. Flytzani-Stephanopoulos, Science 301, 935 (2003).

${ }^{2}$ M. Jobbágy, F. Mariño, B. Schönbrod, G. Baronetti, and M. Laborde, Chem. Mater. 18, 1945 (2006).

${ }^{3}$ A. Karakoti, N. Monteiro-Riviere, R. Aggarwal, J. Davis, R. Narayan, W. Self, J. McGinnis, and S. Seal, JOM 60, 33 (2008).

${ }^{4}$ D. Bera, S. V. N. T. Kuchibhatla, S. Azad, L. Saraf, C. M. Wang, V. Shutthanandan, P. Nachimuthu, D. E. McCready, M. H. Engelhard, O. A. Marina, D. R. Baer, S. Seal, and S. Thevuthasan, Thin Solid Films 516, 6088 (2008)

${ }^{5}$ Y. J. Kim, S. Thevuthasan, V. Shutthananadan, C. L. Perkins, D. E. McCready, G. S. Herman, Y. Gao, T. T. Tran, S. A. Chambers, and C. H. F. Peden, J. Electron Spectrosc. Relat. Phenom. 126, 177 (2002).

${ }^{6}$ Z. Q. Yu, S. V. N. T. Kuchibhatla, M. H. Engelhard, V. Shutthanandan, C. M. Wang, P. Nachimuthu, O. A. Marina, L. V. Saraf, S. Thevuthasan, and S. Seal, J. Cryst. Growth 310, 2450 (2008).

${ }^{7}$ T. Mori, R. Buchanan, D. Ou, F. Ye, T. Kobayashi, J.-D. Kim, J. Zou, and J. Drennan, J. Solid State Electrochem. 12, 841 (2008).

${ }^{8}$ Y. Zheng, Y. Shi, H. Gu, L. Gao, H. Chen, and L. Guo, Mater. Res. Bull. 44, 1717 (2009)

${ }^{9}$ B. Elyassi, N. Rajabbeigi, A. Khodadadi, S. S. Mohajerzadeh, and M. Sahimi, Sens. Actuators B 103, 178 (2004).

${ }^{10}$ S. Gupta, S. V. N. T. Kuchibhatla, M. H. Engelhard, V. Shutthanandan, P. Nachimuthu, W. Jiang, L. V. Saraf, S. Thevuthasan, and S. Prasad, Sens. Actuators B 139, 380 (2009).

${ }^{11}$ Y. J. Kim, Y. Gao, G. S. Herman, S. Thevuthasan, W. Jiang, D. E. McCready, and S. A. Chambers, J. Vac. Sci. Technol. A 17, 926 (1999).

${ }^{12}$ N. Savvides, A. Thorley, S. Gnanarajan, and A. Katsaros, Thin Solid Films 388, 177 (2001).

${ }^{13}$ F. Wu, A. Pavlovska, D. J. Smith, R. J. Culbertson, B. J. Wilkens, and E. Bauer, Thin Solid Films 516, 4908 (2008).

${ }^{14}$ A. G. Zaitsev, G. Ockenfuss, D. Guggi, R. Wordenweber, and U. Kruger, J. Appl. Phys. 81, 3069 (1997).

${ }^{15}$ M. Baudin, M. Wójcik, and K. Hermansson, Surf. Sci. 468, 51 (2000).

${ }^{16}$ N. V. Skorodumova, M. Baudin, and K. Hermansson, Phys. Rev. B 69, 075401 (2004).

${ }^{17}$ M. Nolan, S. Grigoleit, D. C. Sayle, S. C. Parker, and G. W. Watson, Surf. Sci. 576, 217 (2005)

${ }^{18}$ Z. Yang, T. K. Woo, M. Baudin, and K. Hermansson, J. Chem. Phys. 120, 7741 (2004).

${ }^{19}$ J. Conesa, Surf. Sci. 339, 337 (1995).

${ }^{20}$ A. Siokou and R. M. Nix, J. Phys. Chem. B 103, 6984 (1999).

${ }^{21}$ M. Nolan, J. E. Fearon, and G. W. Watson, Solid State Ionics 177, 3069 (2006).

${ }^{22}$ T. X. T. Sayle, S. C. Parker, and C. R. A. Catlow, Surf. Sci. 316, 329 
(1994).

${ }^{23}$ H. Nörenberg and J. H. Harding, Surf. Sci. 477, 17 (2001).

${ }^{24}$ P. W. Tasker, J. Phys. C 12, 4977 (1979).

${ }^{25}$ G. S. Herman, Phys. Rev. B 59, 14899 (1999).

${ }^{26}$ Y. Gao, G. S. Herman, S. Thevuthasan, C. H. F. Peden, and S. A. Chambers, J. Vac. Sci. Technol. A 17, 961 (1999).

${ }^{27}$ S. V. N. T. Kuchibhatla, P. Nachimuthu, F. Gao, W. Jiang, V. Shutthanandan, M. H. Engelhard, S. Seal, and S. Thevuthasan, Appl. Phys. Lett. 94 204101 (2009)

${ }^{28}$ H. R. Fallah, M. Ghasemi, A. Hassanzadeh, and H. Steki, Physica B 373, 274 (2006)

${ }^{29}$ Y. Igasaki and H. Saito, J. Appl. Phys. 70, 3613 (1991).

${ }^{30} \mathrm{P}$. Thilakan and J. Kumar, Vacuum 48, 463 (1997).
${ }^{31}$ T. Burmann, J. Geerk, O. Meyer, R. Schneider, and G. Linker, Solid State Commun. 90, 599 (1994).

${ }^{32}$ S. A. Chambers, Adv. Mater. 22, 219 (2010).

${ }^{33}$ M. Ohring, The Materials Science of Thin Films (Academic, New York, 1992).

${ }^{34}$ S. A. Chambers, Surf. Sci. Rep. 39, 105 (2000).

${ }^{35}$ Y. Chen, D. M. Bagnall, H.-j. Koh, K.-t. Park, K. Hiraga, Z. Zhu, and T. Yao, J. Appl. Phys. 84, 3912 (1998).

${ }^{36}$ G. Linker, R. Smithey, J. Geerk, F. Ratzel, R. Schneider, and A. Zaitsev, Thin Solid Films 471, 320 (2005).

${ }^{37}$ D. C. Sayle, T. X. T. Sayle, S. C. Parker, C. R. A. Catlow, and J. H. Harding, Phys. Rev. B 50, 14498 (1994). 